ARAŞTIRMA / RESEARCH

\title{
Safen ven yetmezliklerinin n-butil siyanoakrilat embolizasyonu ile tedavisi: tek merkez bulguları
}

Treatment of saphenous vein insufficiency with n-butyl cyanoacrylate embolization: one center experience

Cengiz Oval1

Eskişehir Osmangazi Üniversitesi Tip Fakültesi, Kalp ve Damar Cerrahisi, Eskişehir, Turkey

Cukurova Medical Journal 2018;43(4):886-891

Abstract

Purpose: The aim of this study was to present our results obtained from the patients with advanced saphenous vein insufficiency and treated with N- butyl cyanoacrylate embolization (CAE).

Material and Methods: In the present study, we included 205 patients admitted to our clinic with advanced saphenous vein insufficiency and treated with CAE. All patients were evaluated preoperatively according to CEAP (Clinical severity, Etiology, Anatomy, Pathophysiology) classification. The patients were rechecked and, their clinics and quality of life were assessed at $1 \mathrm{st}, 3 \mathrm{rd}$, and 6 th months after the surgery. Moreover, results of their color Doppler ultrasounds (CDUS) obtained right after and 6 months after the operation were compared. The presence of the total occlusion in the vein treated was considered as a successful intervention.

Results: While total occlusions of the veins were detected in the examinations of the Doppler Ultrasounds obtained right after the surgery in all the patients $(100 \%)$, the examinations of the Doppler Ultrasounds taken at 6th months after the surgery indicated that one of the patients developed partial recanalization and minimal reflux $(0.5 \%)$. However, 28 patients possessed various extend of complications (13\%). Ultimately, while $90-96 \%$ of the patients expressed improvement in their sense of pain, burning, fatigue, and itching symptoms, 2 patients $(1 \%)$ expressed deterioration in such symptoms at 6th month after the surgery.

Conclusion: Our present results suggest that Cyanoacrylate embolization can be used safely in the treatment of advanced saphenous vein insufficiency since it provides high occlusion rates with success, rare complications and offers better comfort to the patients.

Key words: Saphenous vein, varices, cyanoacrylate, endovenous treatment

\section{Öz}

Amaç: $\mathrm{Bu}$ çalışmanın amacı $\mathrm{N}$ - butil siyanoakrilat embolizasyon (CAE) ile tedavi ettiğimiz ileri dereceli safen ven yetmezliklerindeki sonuçlarımızı sunmaktır.

Gereç ve Yöntem: Kliniğimizde ileri dereceli safen ven yetmezliği nedeniyle CAE ile tedavi ettiğimiz 205 hasta çalışmaya dâhil edildi. Tüm hastalar CEAP (Clinical severity, Etiology, Anatomy, Pathophysiology) sinıflandırmasına göre ameliyat öncesi değerlendirildi. Postoperatif dönemde hastaların 1,3 ve 6 . aylarda kontrolleri yapılarak, klinik ve yaşam kalitesi değerlendirildi. Operasyon sonrası ve 6. aydaki yapılan Renkli Doppler Ultrasonografi (RDUS) sonuçları karşılaştırıldı. İşlemin uygulandığı damarın total oklüzyonu operasyonun başarısı olarak tanımlandı.

Bulgular: Operasyon sonrasi yapilan Doppler Ultrasonografi incelemelerinde hastalarin tamaminda safen vende total oklüzyon saptanirken (\%100) 6. ayda yapilan Doppler Ultrasonografi incelemelerinde ise 1 hastada k1smı rekanalizasyon ve minimal reflü $(\% 0,5)$ tespit edildi. 28 hastada (\%13) istenmeyen olay - komplikasyon gelişti. Hastalar; ağrı, yanma, yorgunluk hissi, kașıntı gibi semptomlarda 6. ayda \% $90-96$ iyileşme olduğunu ifade ederken sadece 2 hasta (\%1) kötüleşme olduğunu belirtti. Sonuç: Siyanoakrilat Embolizasyon; yüksek oklüzyon ve başarı oranları, oldukça az komplikasyon ve yüksek hasta konforu sağlaması nedeniyle safen ven yetmezliklerinin tedavisinde güvenle kullanılabileceği kanaatindeyiz.

Anahtar kelimeler: Safen ven, varis, siyanoakrilat, endovenöz tedavi. 


\section{GİRİ̧}

Yüzeyel venöz sistem yetersizlikleri toplumda oldukça yaygın olup kadınların \%25 inde, erkeklerin ise $\% 15$ inde görülür. Telenjiektazi şeklinde sadece kozmetik bir sorun olarak karşımıza çıkabileceği gibi, ülser gibi ciddi cilt değişikliklerine de neden olabilmektedir. Başlıca semptomlar; ağrı, şşslik, gece krampları, sicaklık ve yanma hissi, yorgunluk hissi, huzursuzluk, kaşınma ve karıncalanmadır ${ }^{1}$. Tanı ve takipte en çok Renkli Doppler Ultrasonografi (RDUS) kullanılır ve bununla venöz yetmezliğin şiddeti, seviyesi, akım şekli, anormal damarsal yapılar, venlerin çap ve morfolojileri rahatlıkla gösterilebilir ${ }^{2}$. Tedavide amaç; reflünün ortadan kaldırılması olmalıdır. Uzun yıllar ligasyon ve stripping gibi cerrahi yöntemler standart tedavi olarak uygulanmış olmakla birlikte son yıllarda lazer ablasyon (EVLA), radyofrekans ablasyon (RFA) ve n-butil siyanoakrilat embolizasyon (CAE) gibi endovenöz girişimler yaygin kullanım alanı bulmuştur ${ }^{3,4}$.

N-Butil Siyanoakrilat (CA); intrakranial arteriovenöz malformasyonlar ${ }^{5}$, varikoseller ${ }^{6}$, siroza bağl1 kanamalar $^{7}$ ve alt ekstremite yüzeyel ven yetmezlikleri $^{8}$ gibi pekçok alanda son yıllarda yaygin kullanım alanı bulmuştur. CA; kan ve doku ile teması halinde polimerizasyon ile bağlayıcı bir zar haline dönüşerek güçlü bir doku bağ1 oluştur ve incompotent venin oklüzyonunu sağlar. Yaklaşık 2,5 dakika sonra maksimum bağlanma mukavemeti elde edilir. Bu özelliğinin yanında CA; yüksek vizkoziteye ve yeterli elastisiteye sahiptir. Hizlı ilk polimerizasyon sayesinde ( $<5 \mathrm{sn})$ derin damarların embolizasyon riskini oldukça azaltır, yeterli elastisite sayesinde ise hareket k1sitlllığ1 yapmaz ve hasta konforunu arttırır ${ }^{9,10}$.

Venöz yetmezlik tedavisinde CA kullanımı giderek yaygınlaşmaktadır ve bu konuda çalışmalar yeni tarihli olarak yayınlanmaya başlamıştır. Ancak CA kullanımı ile ilgili literatürde, özellikle büyük hasta popülasyonlarında ve farklı merkezlerden çalışmaların ihtiyacı vardır. Bu çalışmada amacımız; kliniğimizde geniş hasta popülasyonunda CA embolizasyon ile tedavi ettiğimiz ileri dereceli safen ven yetmezliklerindeki sonuçlarımızı sunmaktır.

\section{GEREÇ VE YÖNTEM}

Ocak 2016-Haziran 2017 tarihleri arasında Eskişehir Osmangazi Üniversitesi Tip Fakültesi Hastanesi
Kalp ve Damar Cerrahisi Kliniğine ileri dereceli safen ven yetmezliği nedeniyle gelen ve CAE ile tedavi edilen ardışık 205 hasta çalışmaya dâhil edildi. Tüm hastalar CEAP (Clinical severity, Etiology, Anatomy, Pathophysiology) sinıflandırmasina göre ameliyat öncesi değerlendirildi. CEAP sınıflandırması 1994 yılında Amerikan Venöz Forum tarafindan kabul gören anket ile yapılmıştır. Anket formu; venöz yetmezlik hastalarında olabilecek bütün klinik bulguları içermekle birlikte, kontrol sonrası sayısal skorlamayı da içermektedir. Aynı zamanda etiyolojik, anatomik ve patofizyolojik kontroller ve skorlamalar da bulunmaktadır ${ }^{11,12}$.

Hastaların ameliyat öncesi ve sonrası 1,3 ve 6 . aylarda kontrolleri yapılarak, klinik ve yaşam kalitesi değerlendirildi. Tüm kontrollerde Venous Clinical Severity Score (VCSS) klinik skorlama sistemi anketi ile veriler kayıt altına alındı (0 skoru önemli bir venöz hastalığ göstermemektedir ve 30 en şiddetli skordur). Hastaların yaşam kalitesi değerlendirmesi hastalar tarafindan 6. ayda Aberdeen Varicose Vein Questionnaire (AVVQ) anket formu doldurularak ölçüldü. AVVQ anket formunda 13 sorunun toplam puanı, 0'dan 100 puana kadar değişmektedir; 0 puan, mümkün olan en iyi yaşam kalitesini göstermektedir ${ }^{13}$. Operasyon sonrası ve 6 . aydaki yapılan RDUS sonuçları karşılaştırıldı. İşlemin uygulandığı damarın total oklüzyonu operasyonun başarısı olarak tanımlandı.

Çalışmaya dahil edilme kriterleri vena safena magna (VSM) da orta veya ileri derecede yetmezlik olması, hastanın semptomatik olması, VSM çapının safenofemoral bileşkenin $2 \mathrm{~cm}$ distalinde 5,5-14 $\mathrm{mm}$ arasinda olması, sadece VSM ve dallarında yetmezlik olmasıydı. Çalışmadan dışlama kriterleri, derin venöz tromboz (DVT), arteriovenöz malformasyon, ileri immobilite, VSM da ileri derecede tortuosite, orta ve ileri derin venöz yetmezlik olması, VSM nin $14 \mathrm{~mm}$ ve üzeri dilate olması, VSM çapının 5,5 mm'den az olması, eski ve yeni başlamış ileri derecede tromboflebiti olması, ameliyatı yapılmış olmasına rağmen takiplerinin yapilamamasiydi..

Ekimoz, ağr1, endurasyon, parestezi, yüzeyel tromboflebit ve ciltte geçici renk değişikliği gibi basit tıbbi müdahale ile geçebilecek durumlar minör komplikasyon olarak; motor sinir hasarı, büyük arter ve ven yaralanması, cilt yanığı, arteriyovenöz fistül oluşumu, DVT ve pulmoner tromboemboli gibi yakin izlem gerektiren durumlar ise major komplikasyon olarak kabul edildi. 
Tablo 1. Demografik ve klinik özellikler

\begin{tabular}{|c|c|}
\hline & $\begin{array}{c}\text { (n)(ort } \pm \text { std)(min - } \\
\text { max })\end{array}$ \\
\hline Yaș (y1l) & $49.32 \pm 15.60(18-79)$ \\
\hline Erkek / Kadın & $82 / 119$ \\
\hline Sağ / Sol & $92 / 113$ \\
\hline $\begin{array}{l}\text { Semptomların ortalama } \\
\text { süresi (y1) }\end{array}$ & $9.16 \pm 3.12(2-17)$ \\
\hline CEAP Sinıflamas1 & $\mathrm{n}$ \\
\hline \multicolumn{2}{|l|}{$\mathrm{C}$ (Klinik) } \\
\hline $\mathrm{C} 2-\mathrm{C} 4$ & 184 \\
\hline $\mathrm{C} 4-\mathrm{C} 6$ & 21 \\
\hline \multicolumn{2}{|l|}{ E (Etyolojik) } \\
\hline E primer & 205 \\
\hline \multicolumn{2}{|l|}{ A (Anatomik) } \\
\hline A yüzeyel & 81 \\
\hline A yüzeyel+perforan & 124 \\
\hline \multicolumn{2}{|l|}{$\mathrm{P}$ (patofizyolojik) } \\
\hline P reflü & 205 \\
\hline
\end{tabular}

\section{Siyanoakrilat embolizasyonu prosedürü}

(CEA)

Siyanoakrilat embolizan ajan uygulanan tüm hastalara işlem Kalp Damar Cerrahisi ameliyathanesinde yapıldı. RDUS klavuzluğunda diz seviyesinde uygun bir bölgeden vena safena magnaya Seldinger tekniğiyle lokal anestezi altında ponksiyon yapıldı ve $7 \mathrm{~F}$ sheat yerleştirildi. Tüm hastalarda İnvamed VenaBLOCK (Ankara, Türkiye) embolizan ajan sistemi kullanıldı. Sisteme ait katater safenofemoral bileşkenin yaklaşık $3 \mathrm{~cm}$ distaline kadar ilerletildi. Hasta trendelenburg pozisyonuna alınd 1 ve safeno-femoral bileşke RDUS probu ile bastırılarak kollabe edildi. Yaklaşı 30 saniye içinde Safen ven trasesi boyunca kesintisiz olarak CA enjekte edildi ve eş zamanlı olarak dişarıdan bası uygulandı. Enjeksiyon bitiminden 3-4 dakika sonra basilar sonlandırıldı. Ardından ven çapındaki azalma ve ven duvarındaki ekojenite artışı RDUS ile kontrol edildi. İşlem bu noktaya kadar ortalama olarak 18.5 \pm 4.4 dakika sürdü ve hastalar aynı gün taburcu edildi. Hiçbir hastaya elastik bandaj uygulanmadı ve varis çorabı giydirilmedi.

\section{İstatistiksel analiz}

Sürekli veriler ortalama \pm standart sapma olarak ifade edilmiştir. Kategorik veriler yüzde olarak verilmiştir (\%). Verilerin normal dağılıma uygunluğunu araştırmak için Shapiro Wilk testi kullanılmıştır. Normal dağılıma sahip grupları karşılaştırırken iki gruptaki olgulara bağımsız örnek t testi analizi uygulanmıştır.

Pearson Chi-Square ve Pearson Tam Chi-Square ve Fisher'ın Tam Chi-Kare analizi, oluşturulan çapraz karşılaştırma tabloları için yapılmıştır. Analiz için IBM SPSS Statistics 21.0 (IBM Corp. 2012. Windows IBM SPSS Statistics, Sürüm 21.0, Armonk, NY: IBM Corp.) programları kullanıldı. İstatistiksel olarak anlamlılık için $\mathrm{p}<0.05$ değeri kriter olarak seçildi.

Tablo 2. İşlemle ilgili sonuçlar.

\begin{tabular}{|l|c|}
\hline & $\begin{array}{c}\text { (n)(ort } \mathbf{\pm} \text { std)(min } \\
\text { - max) }\end{array}$ \\
\hline VSM proksimal çap1 (mm) & $7.0 \pm 1,52(5.5-14)$ \\
\hline İşlem yapilan VSM uzunluğu (cm) & $45 \pm 5.62(21-54)$ \\
\hline Anestezi tipi & Lokal \\
\hline CA miktarı (ml) & $1.8(1-2)$ \\
\hline İşlem süresi (dakika) & $18.50 \pm 4.42(10-$ \\
& $41)$ \\
\hline Taburculuk süresi (saat) & $4 \pm 2.1$ \\
\hline $\begin{array}{l}\text { Operasyon sonrası RDUS } \\
\text { VSM'da oklüzyon }\end{array}$ & 205 \\
\hline $\begin{array}{l}\text { 6. ay RDUS } \\
\text { Rekanalizasyon ve reflü }\end{array}$ & 1 \\
\hline
\end{tabular}

CA: Siyanoakrilat, RDUS: Renkli Doppler Ultrasonografi, VSM: Vena Safena Magna

Tablo 3. Komplikasyonlar

\begin{tabular}{|l|c|c|}
\hline & $\mathbf{n}$ & $\mathbf{0}$ \\
\hline $\begin{array}{l}\text { Komplikasyon gelişen } \\
\text { hasta sayıs1 }\end{array}$ & 28 & 13 \\
\hline Derin Ven Trombozu & 0 & 0 \\
\hline Cilt yanı̆̆1 & 0 & 0 \\
\hline Tromboflebit & 2 & 1 \\
\hline Selülit & 2 & 1 \\
\hline Şiddetli Ağr1 & 8 & 4 \\
\hline Parestezi & 0 & 0 \\
\hline Ekimoz & 19 & 9 \\
\hline Hassasiyet & 21 & 10 \\
\hline Endurasyon & 8 & 4 \\
\hline Ödem & 2 & 1 \\
\hline Pigmentasyon artış1 & 3 & 1 \\
\hline Hematom & 0 & 0 \\
\hline
\end{tabular}

\section{BULGULAR}

Hastaların ortalama yaşı 49.32 yıl olup 82'si erkek 113’ü kadın idi. Tedavi uygulanan tüm hastalar semptomatikti. Ağr1 tüm hastalarda bulunan ortak semptomdu. Semptomların ortalama süresi 9 yıl idi (Tablo 1) Hastaların özgeçmişleri incelendiğinde, 2 hastada Romatoid artirit, 7 hastada psöriatik artrit, 9 hastada psöriazis, 1 hastada malignite, 39 hastada 
hipertansiyon ve 26 hastada diyabet vardi. 74 hastanın (\% 36) birinci derece akrabalarında varis hikâyesi mevcuttu. 119 kadın hastanın 95’i (\%79) 16 arasında doğum yapmıştı. 92 hastanın sağ (\%45), 113 hastanın ise sol (\%55) VSM yetmezliği mevcuttu. RDUS incelemede, ekstremitelerin hiçbirinde derin ven yetmezliği, derin ven trombozu ve arteryel yetmezlik bulgusu saptanmadi. CEAP siniflamasina göre C2-C4 arası 184 hasta (\%90), C4-C6 aras1 21 hasta (\%10) vardi. Hastalarda semptomların görülme süresi ortalama olarak $9.16 \pm 3.12$ yll idi. (Tablo 1). Safen ven proksimal çapları (ortalama $7 \pm 1,52 \mathrm{~mm}$ ) ve işlem yapılan safen ven uzunluğu (ortalama $45 \pm 5,62 \mathrm{~cm}$ ) idi. Kullanilan CA miktarı ortalama $1.8 \mathrm{ml}$ (min: 1max:2 ml) idi. İşlem süresi ortalama olarak $45 \pm$ $4.42 \mathrm{dk}$ iken taburculuk süresi $4 \pm 2.1$ saat idi. Operasyon sonrası yapilan RDUS incelemelerinde hastaların tamamında safen vende total oklüzyon saptanırken 6. ayda yapilan RDUS incelemelerinde ise 1 hastada kısmı rekanalizasyon ve minimal reflü tespit edildi. (Tablo 2). 28 hastada (\%13) istenmeyen olay - komplikasyon gelişti. Derin ven trombozu, pulmoner emboli, cilt yanı̆̆1 gibi majör komplikasyonlar hiçbir hastada görülmedi. Minör komplikasyonlardan hassasiyet $(\% 12)$, ekimoz ( $\%$ 10), şiddetli ağrı (\% 4) ve endurasyon (\% 4) en s1k görülen komplikasyonlar idi. (Tablo 3). Hastalardaki ağrı, yanma ve yorgunluk hissi, kramp, şişlik, kaşıntı, uyuşma ve renk değişimi gibi semptomlarda 6 . ayda $\% 90$ - 96 iyileşme görülürken sadece 2 hastada (\%1) kötüleşme oldu. (Tablo 4). VCSS; preoperatif : $5.61 \pm 1.10$, postoperatif 6.ay: $1.03 \pm 0.96$ idi. AVVQ; preoperatif : $18.23 \pm 6.80$, postoperatif 6.ay: $4.89 \pm 1.62$ idi. (Tablo 5).

Tablo 4: Semptomların işlem sonrası 6. aydaki değişimi

\begin{tabular}{|c|c|c|c|c|c|c|}
\hline Semptomlar & \multicolumn{2}{|c|}{ İyileşme } & \multicolumn{2}{|c|}{ Değişim yok } & \multicolumn{2}{|c|}{ Kötüleşme } \\
\hline & $\%$ & $\mathrm{n}$ & $\%$ & $\mathrm{n}$ & $\%$ & $\mathrm{n}$ \\
\hline Ağr1 & 95 & 194 & 4 & 9 & 1 & 2 \\
\hline Yanma Hissi & 95.5 & 195 & 4 & 9 & 0.5 & 1 \\
\hline Yorgunluk Hissi & 96 & 197 & 3.5 & 7 & 0.5 & 1 \\
\hline Kramp & 95.5 & 195 & 4 & 8 & 1 & 2 \\
\hline Şişlik & 94 & 193 & 5 & 10 & 1 & 2 \\
\hline Kaşıntı & 90 & 185 & 8 & 16 & 2 & 4 \\
\hline Uyuşma & 92 & 189 & 5.5 & 11 & 2.5 & 5 \\
\hline Renk değişimi & 90 & 185 & 9.5 & 19 & 0.5 & 1 \\
\hline
\end{tabular}

Table 5. Klinik Değerlendirme

\begin{tabular}{|l|c|}
\hline & CAE \\
\hline VCSS & \\
\hline Pre-op & $5.61 \pm 1.10$ \\
\hline Post-op 6. ay & $1.03 \pm 0,96$ \\
\hline AVVQ & $18.23 \pm 6.80$ \\
\hline Pre-op & $4.89 \pm 1.62$ \\
\hline Post-op 6. ay & \\
\hline
\end{tabular}

CAE: Siyanoakrilat Embolizasyon, VCSS: Venöz Klinik Şiddet Skoru, AVVQ: Aberdeen Varicose Veins Questionnaire

\section{TARTIŞMA}

Safen ven yetmezliklerin tedavisinde skleroterapi, RFA, EVLA ve CAE gibi minimal invaziv tedaviler son yillarda ön plana çıkmıştır. Van Den Bos ve ark. yayınlamış olduğu bir meta-analizde 64 çalışmada 12.320 işlem yapılmış ve 3 yılın sonundaki başarı oranlarını; striping yapılanlarda $\% 78$, köpük skleroterapi yapilanlarda $\% 77$, RFA yapilanlarda $\%$ 84 ve EVLA yapilanlarda ise \% 94 olarak tespit etmişlerdir ${ }^{14}$. Bu sonuçlara göre minimal invaziv tekniklerin alt ekstremite varislerinin tedavisinde en az cerrahi kadar etkili olduğu sonucuna varmışlardır ${ }^{14-16}$. Minimal invaziv yöntemlerin yüksek başarı oranlarının yanında uygulama kolaylığı, komplikasyonların daha az olması, hastanede kalış süresinin daha kısa olması, daha çabuk mobilizasyon, daha az ağrı gibi nedenlerden dolay1 günümüzde s1klıkla tercih edilen tedavi yöntemleri haline gelmişlerdir ${ }^{14-16}$. 
CA; yaklaşık 30 yıldır intravasküler embolizan ajan olarak kullanılmış olsa da venöz yetmezliklerin tedavisinde kullanımı diğer minimal invaziv tedavilere göre oldukça yenidir. Son yillarda CAE'nun bu yönde kullanımı ile ilgili makaleler literatürde yerini almaya başlamıştır ve \% $92-99$ arasında oklüzyon sağlayarak oldukça etkin bir tedavi yöntemi olduğu görülmüştür ${ }^{16-18}$. RFA ve CA'1 karşılaştıran randomize bir çalışma CA'ın RFA kadar etkili olduğunu ve yetmezlik bulunan VSM'nin tedavisinde 3 ayda güvenilir olduğunu göstermiştir 21.Çalışmamızda 205 hastanın tamamında operasyon sonras1 oklüzyon görülürken 6.aydaki RDUS ile yapilan kontrollerinde sadece 1 hastada minimal rekanalizasyon ve hafif derecede reflü olduğu görülmüştür. Başarı oranımız \%99,5 olup literatürle uyumludur.

RFA ve EVLA gibi termal ablasyon esasına dayalı minimal invaziv tedavilerde tümesan anestezi (TA) kullanımı gereklidir. TA ven etrafinda koruyucu bir tabaka oluşturarak perivasküler dokuları ve cildi yüksek sıcaklıktan korur. Ancak ağr1, hematom ve ekimoz gibi istenmeyen olaylar1 da arttırır ${ }^{14,19,20}$. CAE tedavisinde TA ihtiyac1 yoktur ${ }^{10}$. Çalışmamızdaki hastalarda TA kullanılmadığından ve genel yada spinal anestezi yerine lokal anestezi ile işlem gerçekleştirildiğinden anesteziye ve TA ya bağl1 oluşabilecek komplikasyonlar oluşmamıştır.

Yapılmış olan çalışmalarda minimal invaziv yöntemlerde komplikasyonların daha az olduğu, hastanede kalış süresinin daha kısa olduğu, daha çabuk mobilizasyon sağlandığ1 görülmektedir ${ }^{14-16}$. Çalık ve ark. larının CAE ile 181 hasta üzerinde yapmış oldukları çalışmada 11 hastada ağrı (6.1\%) ve 1 hastada tromboflebit $(0.5 \%)$ oluşmuştur ${ }^{10}$. Bizim çalışmamızda da Çalık ve ark.larının çalışmasında olduğu gibi derin venöz tromboz, pulmoner emboli gibi majör komplikasyonlar oluşmamıştır. Minör komplikasyon olarak nitelediğimiz ekimoz 21 hastada $(\% 10)$ ve hassasiyet ise 24 hastada (\%12) oluşmuştur ve bunlar ponksiyon bölgesinde lokalizedir. Nispeten daha önemli görülebilecek flebit, selülit gibi komplikasyonlar ise \%1'ler seviyesindedir.

Çalışmamızda ortalama işlem süresi 18,5 dk iken ortalama hospitalizasyon süresi ise 4 saattir. Bu şekilde erken dönemde mobilizasyon sağlanarak hasta konforu artmakta ve maliyet de azaltmaktadır.

6.ayda yapılan RDUS'de oklüzyon oranları ve reflünün olmaması $(\% 99,5)$ çalışmamızda CAE'nun etkinliğini objektif olarak göstermektedir. Hastalardaki semptomların tedavi sonrası değişimi sübjektif olarak değerlendirilebilmektedir. 6.ayda hastaların sadece \%1'i semptomlarda kötüleşmeyi ifade ederken tam iyileşmeyi ifade edenlerin %90-96 olması etkinlik ve başarı açısından önemlidir.

Çalışma kapsamında safen ven yetmezliğine dair geniş hasta popülasyonuna sahip, tek merkezli bir tecrübe rapor etsek de, bu çalışmanın çeşitli sınırlamaları vardır. Bu çalışmanın en önemli kısıtlamaları kısa süreli takip süresi ile retrospektif bir analizin olmasıdır. Üçüncü günde ve 1,3 ve 6 . aylarda yapılan kısa takip süreli klinik rutin takip, hastanın belirtileri hakkında yeterli bilgi vermeyebilir. Yine sadece büyük safen venin kapalılık oranına odaklanılmıştır ve gözle görülebilir variköz venlerin kaybolması ve variköz venlerin tekrarı analiz edilmemiştir. Tedavi maliyeti ve işe geri dönüş ile ilgili masraflar da dahil olmak üzere genel tedavi maliyetleri analiz edilmemiştir.

Bulgular dahilinde, safen ven yetmezliklerinin tedavisinde CAE; yüksek oklüzyon ve başarı oranları, oldukça az komplikasyon ve yüksek hasta konforu sağlandığ1 gözlenmektedir. Bu sonuçlar, uzun vadeli sonuçlar ile ve daha geniş hasta guruplarındaki çalışmalarla desteklenmelidir.

\section{KAYNAKLAR}

1. Callam MJ. Epidemiology of varicose veins. $\mathrm{Br} \mathrm{J}$ Surg. 1994;81:167-73.

2. Labropoulos N, Tiongson J, Pryor L, Tassiopoulos AK, Kang SS, Ashraf Mansour M et al. Definition of venous reflux in lower-extremity veins. J Vasc Surg. 2003;38:793.

3. Puggioni A, Kalra M, Carmo M, Mozes G, Gloviczki P. Endovenous laser therapy and radiofrequency ablation of the great saphenous vein: analysis of early efficacy and complications. J Vasc Surg. 2005;42:48893.

4. Santler B, Goerge T. Chronic venous insufficiency a review of pathophysiology, diagnosis, and treatment. J Dtsch Dermatol Ges. 2017;15:538-56.

5. Heit JJ, Faisal AG, Telischak NA, Choudhri O, Do HM. Headway Duo microcatheter for cerebral arteriovenous malformation embolization with nBCA. J Neurointerv Surg. 2016;8:1181-5.

6. Bilreiro C, Donato P, Costa JF, Agostinho A, Carvalheiro V, Caseiro-Alves F. Varicocele embolization with glue and coils: A single center experience. Diagn Interv Imaging. 2017;98:529-34.

7. Honrubia López R, Barbado Cano A, Ruiz Fernández G, Bustamante Robles KY. A bronchobiliary fistula treated with cyanoacrylate glue 
in a patient with liver cirrhosis. Rev Esp Enferm Dig. 2017;109:288.

8. Kolluri R, Gibson K, Cher D, Madsen M, Weiss R, Morrison N. Roll-in phase analysis of clinical study of cyanoacrylate closure for incompetent great saphenous veins. J Vasc Surg Venous Lymphat Disord. 2016;4:407-15.

9. Chan YC, Law Y, Cheung GC, Cheng SW. Predictors of Recanalization for Incompetent Great Saphenous Veins Treated with Cyanoacrylate Glue. J Vasc Interv Radiol. 2017;28:665-71.

10. Çalık ES, Arslan Ü, Ayaz F, Tort M, Yıldız Z, Aksu $\mathrm{V}$, et al. N-butyl cyanoacrylate in the treatment of venous insufficiency--the effect of embolisation with ablative polymerisation. Vasa. 2016;45:241-6.

11. Padberg FT Jr. CEAP classification for chronic venous disease. Dis Mon. 2005;51:176-82.

12. Gloviczki P, Yao JST(ed) Handbook of venous disorders,2nd edition Arnold publishers. 2001.

13. Garratt AM, Macdonald LM, Ruta DA, Russell IT, Buckingham JK, Krukowski ZH. Towards measurement of outcome for patients with varicose veins. Qual Health Care. 1993;2:5e10.

14. Van den Bos R, Arends L, Kockaert M, Neumann M, Nijsten T. Endovenous therapies of lower extremity varicosities: a meta-analysis. J Vasc Surg. 2009;49:230.

15. Nesbitt C, Bedenis R, Bhattacharya V, Stansby G. Endovenous ablation (radiofrequency and laser) and foam sclerotherapy versus open surgery for great saphenous vein varices. Cochrane Database Syst Rev.
2014;30;CD005624.

16. Carroll C, Hummel S, Leaviss J, Ren S, Stevens JW, Cantrell A et al. Systematic review, network metaanalysis and exploratory cost-effectiveness model of randomized trials of minimally invasive techniques versus surgery for varicose veins. Br J Surg. 2014;101:1040-52.

17. Ravi R, Trayler EA, Barrett DA, Diethrich EB. Endovenous thermal ablation of superficial venous insufficiency of the lower extremity: single-center experience with $3000 \mathrm{limbs}$ treated in a 7 -year period. J Endovasc Ther. 2009;16:500-5.

18. Uncu H, Ocak FT, Karaca S, Badak TO, Özsöyler İ. Variköz ven cerrahisinde $980 \mathrm{~nm}$ dalga boyu endovenöz lazer ablasyon ve radyofrekans ablasyonun orta dönem sonuçlarının karșılaştırılması. Türk Gögüs Kalp Damar Cerrahisi Dergisi. 2015;23:678-82.

19. Ostler AE, Holdstock JM, Harrison CC, Price BA, Whiteley MS. Strip-tract revascularization as a source of recurrent venous reflux following high saphenous tie and stripping: results at 5-8 years after surgery. Phlebology. 2015;30:569-72.

20. Anwar M.A, Lane T.R, Davies A.H, Franklin I.J. Complications of radiofrequency ablation of varicose veins. Phlebology, 2012;27:34-9.

21. Morrison N, Gibson K, McEnroe S, Goldman M, King T, Weiss $\mathrm{R}$ et al. Randomized trial comparing cyanoacrylate embolisation and radiofrequency ablation for incompetent great saphenous veins (VeClose). J Vasc Surg. 2015;61:985-94. 